\section{Foods rich in magnesium}

Keywords: magnesium, soybeans, dried herbs, chocolate, cocoa, sesame seeds

\section{Opinion}

\section{Bran (Rice, Wheat and Oat)}

Rice, Wheat, and Oat bran are great additions to breads and breakfast cereals like oats, rye, and buckwheat. One cup of crude rice bran contains $922 \mathrm{mg}$ of magnesium $(230 \% \mathrm{DV})$ which is $781 \mathrm{mg}$ (195\% DV) per 100 gram serving. Crude wheat bran contains $354 \mathrm{mg}$ of magnesium ( $89 \% \mathrm{DV})$ per cup, or $611 \mathrm{mg}(153 \% \mathrm{DV})$ per 100 gram serving. Crude oat bran contains $220 \mathrm{mg}$ of magnesium $(55 \% \mathrm{DV})$ per cup, or $235 \mathrm{mg}$ magnesium (59\% DV) per 100 gram serving.

\section{Dried herbs}

Dried herbs are packed with vitamins and a healthy addition to almost any meal. Dried Coriander provides the most magnesium with $694 \mathrm{mg}(174 \%$ DV) per 100 gram serving, or $14 \mathrm{mg}$ (3\% DV) per tablespoon. It is followed by Chives $(160 \%$ DV), Spearmint $(151 \%$ DV), Dill (112\% DV), Sage (107\% DV), Basil (106\% DV), and Savory (95\% DV).

Squash, pumpkin, and watermelon seeds (Dried or Roasted)

Great as a snack or in a salad, pumpkin, squash, and watermelon seeds are packed with magnesium. Squash and pumpkin seeds provide $535 \mathrm{mg}$ of magnesium (134\% DV) per 100 gram serving, or $738 \mathrm{mg}(185 \% \mathrm{DV})$ per cup. Watermelon seeds provide $515 \mathrm{mg}(129 \% \mathrm{DV})$ of magnesium per 100 gram serving, or 556mg (139\% DV) per cup.

\section{Cocoa powder (Dark Chocolate)}

Dark chocolate is becoming more popular and with good reason, long regarded as junk food dark chocolate is packed with vitamins and conferred health benefits. Cocoa powder provides $499 \mathrm{mg}$ of magnesium $(125 \% \mathrm{DV})$ per 100 gram serving or $429 \mathrm{mg}(107 \% \mathrm{DV})$ per cup. Dark baking chocolate provides $327 \mathrm{mg}$ per 100 gram serving ( $82 \% \mathrm{DV})$, or $95 \mathrm{mg}(24 \% \mathrm{DV})$ per square, and a typical chocolate candy bar provides $63 \mathrm{mg}$ of magnesium $(16 \% \mathrm{DV})$ per 100 gram serving or $28 \mathrm{mg}(7 \% \mathrm{DV})$ per bar.

\section{Flax, sesame seeds, and sesame butter (Tahini)}

Flax and Sesame seeds are a great source of heart healthy oils and also provide a good source of magnesium. Flax seeds provide $392 \mathrm{mg}$ $(92 \% \mathrm{DV})$ per 100 gram serving or $39 \mathrm{mg}(10 \% \mathrm{DV})$ per tablespoon. Sesame seeds provide $351 \mathrm{mg}(88 \% \mathrm{DV})$ per 100 gram serving, or $32 \mathrm{mg}(8 \% \mathrm{DV})$ per tablespoon. Sesame butter (tahini) provides $362 \mathrm{mg}$ of magnesium per 100 gram serving, or $58 \mathrm{mg}$ (14\% DV) per tablespoon.

\section{Brazil nuts}

Possibily the largest of all nuts, Brazil nuts are a great source of magnesium. Brazil nuts provide $376 \mathrm{mg}(94 \% \mathrm{DV})$ of magnesium per 100 gram serving, $500 \mathrm{mg}(125 \% \mathrm{DV})$ per cup, and $19 \mathrm{mg}(5 \% \mathrm{DV})$ in
Volume 8 Issue 2 - 2018

\section{George Grant \\ World organization of Natural Medicine, CEO of Academy of Wellness, Canada}

Correspondence: George Grant, World organization of Natural Medicine, CEO of Academy of Wellness, 17 Waterhouse Way, Richmond Hill, ON L4C 9H8, Ontario, Canada, Tel + I 416562-3140, Email drgrant@rogers.com

Received: January 09, 2018 | Published: March 20, 2018

a single kernel or nut. Brazil nuts are also very high in selenium, so should be eaten moderately.

\section{Sunflower seeds}

Sunflower seeds are the number one source of vitamin E, and a good source of thiamin. Sunflower seeds provide $325 \mathrm{mg}$ (81\% DV) of magnesium per 100 gram serving, or $455 \mathrm{mg}$ (114\% DV) per cup.

\section{Almonds and cashews (Mixed nuts, Pine nuts)}

Nuts are great as a snack or as an addition to salads and soups. Almonds provide $286 \mathrm{mg}$ ( $72 \%$ DV) per 100 gram serving, or $395 \mathrm{mg}$ ( $99 \%$ DV) per cup. Cashews provide $273 \mathrm{mg}$ (68\% DV) per 100 gram serving, or $352 \mathrm{mg}$ ( $88 \% \mathrm{DV})$ per cup. Pine nuts provide $251 \mathrm{mg}(63 \%$ DV) per 100 gram serving, or 339mg ( $85 \%$ DV) per cup. Mixed nuts in general provide $251 \mathrm{mg}(63 \% \mathrm{DV})$ per 100 gram serving, or $361 \mathrm{mg}$ (90\% DV) per cup.

\section{Molasses}

A good substitute for refined sugar in cakes and breads, molasses is also a great source of magnesium. Molasses provides $242 \mathrm{mg}(61 \%$ DV) per 100 gram serving, 816mg (204\% DV) per cup, and $48 \mathrm{mg}$ $(12 \%$ DV) per tablespoon.

\section{Dry roasted soybeans (Edamame)}

Great as a snack or as an addition to salads, dry roasted soybeans are also a great source of magnesium. Dry roasted soybeans provide $228 \mathrm{mg}$ (57\% DV) of magnesium per 100 gram serving, or 392mg $(98 \% \mathrm{DV})$ per cup. When boiled, edamame provides $64 \mathrm{mg}$ ( $16 \% \mathrm{DV})$ of magnesium per $100 \mathrm{~g}$ serving, or $99 \mathrm{mg}$ ( $25 \% \mathrm{DV})$ per cup.

\section{Conclusion}

Magnesium also plays roles in preventing migraine headaches, cardiovascular disease (including high blood pressure, heart attacks, and strokes), sudden cardiac death, and even reduces death from all causes. This important mineral is required by more than 300 different enzymes in your body, which play important roles in the following biochemical processes, many of which are crucial for proper metabolic function: 
i. Creation of ATP (adenosine triphosphate), the energy molecules of your body Proper formation of bones and teeth. Relaxation of blood vessels.

ii. Action of your heart muscle Promotion of proper bowel function Regulation of blood sugar levels.

iii. Low Magnesium Levels Consistently Found in Those with Elevated Insulin.

In just the past year, there have been several significant studies about magnesium role in keeping your metabolism running like a well oiled clock specifically in terms of insulin sensitivity, glucose regulation, and protection from type 2 diabetes.

\section{Acknowledgment}

Author declares no acknowledgment.

\section{Conflict of interest}

Author declares no conflict of interest 